\title{
The Novel Somatostatin Receptor 2/Dopamine Type 2 Receptor Chimeric Compound BIM-23A758 Decreases the Viability of Human GOT1 Midgut Carcinoid Cells
}

\author{
Kathrin Zitzmann ${ }^{\mathrm{a}}$ Sandra Andersen ${ }^{\mathrm{a}}$ George Vlotides $^{\mathrm{a}}$ Gerald Spöttl $^{\mathrm{a}}$ \\ Shengwen Zhang ${ }^{b}$ Rakesh Datta ${ }^{b}$ Michael Culler ${ }^{b}$ Burkhard Göke $^{a}$ \\ Christoph J. Auernhammer ${ }^{\text {a }}$ \\ a Department of Internal Medicine II, University Hospital Campus Grosshadern, Ludwig Maximilians University,

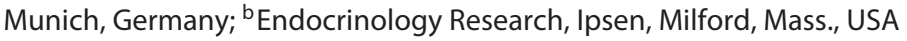

\section{Key Words}

Gastroenteropancreatic system · Neuroendocrine tumors ·

Somatostatin receptors

\begin{abstract}
The majority of neuroendocrine tumors (NETs) of the gastroenteropancreatic system coexpress somatostatin receptors (SSTRs) and dopamine type 2 receptors (D2R), thus providing a rationale for the use of novel SSTR2/D2R chimeric compounds in NET disease. Here we investigate the antitumor potential of the SSTR2/D2R chimeric compounds BIM$23 \mathrm{~A} 760$ and BIM-23A758 in comparison to the selective SSTR2 agonist BIM-23023 and the selective D2R agonist BIM-53097 on human NET cell lines of heterogeneous origin. While having only minor effects on human pancreatic and bronchus carcinoid cells (BON1 and NCl-H727), BIM-23A758 induced significant antitumor effects in human midgut carcinoid cells (GOT1). These effects involved apoptosis induction as well as inhibition of mitogen-activated protein kinase and Akt signaling. Consistent with their antitumor response to BIM-23A758, GOT1 cells showed relatively high expression levels of SSTR2 and D2R mRNA. In particular, GOT1 cells highly express the short transcript variant of D2R. In contrast
\end{abstract}

to BIM-23A758, the SSTR2/D2R chimeric compound BIM$23 \mathrm{~A} 760$ as well as the individual SSTR2 and D2R agonistic compounds BIM-23023 and BIM-53097 induced no or only minor antitumor responses in the examined NET cell lines. Taken together, our findings suggest that the novel SSTR2/ D2R chimeric compound BIM-23A758 might be a promising substance for the treatment of NETs highly expressing SSTR2 and D2R. In particular, a sufficient expression of the short transcript variant of DR2 might play a pivotal role for effective treatment.

(c) 2013 S. Karger AG, Basel

\section{Introduction}

Treatment options for neuroendocrine tumors (NETs) of the gastroenteropancreatic (GEP) system are limited. As more than $85 \%$ of NETs are metastatic at the time of diagnosis, only few patients have a chance for curative surgery. Thus, currently available therapy (bio- and che-

Kathrin Zitzmann and Sandra Andersen contributed equally to this article.

\section{KARGER}

E-Mail karger@karger.com

www.karger.com/nen
(C) 2013 S. Karger AG, Basel

0028-3835/13/0982-0128\$38.00/0
Christoph J. Auernhammer

Department of Internal Medicine II, University Hospital Campus Grosshadern Interdisciplinary Center of Neuroendocrine Tumors of the

GastroEnteroPancreatic System (GEPNET-KUM), Ludwig Maximilians University

Marchioninistrasse 15, DE-81377 Munich (Germany)

E-Mail christoph.auernhammer@med.uni-muenchen.de 
motherapy, surgical, debulking, molecular-targeted therapy, and peptide receptor-based radiotherapy) focuses on symptom control and disease stabilization.

Somatostatin (SST) is a cyclopeptide, consisting of 14 or 28 amino acids (SST-14 and SST-28), which serves as an important physiological inhibitor of endocrine and exocrine secretion $[1,2]$. SST has been shown to affect the release of growth hormone as well as several gastrointestinal tract hormones. SST-14 and SST-28 mediate their effects through interaction with five receptors (SSTR1-5) belonging to the family of $G$ protein-coupled receptors (GPCRs) [3]. All five receptor subtypes have been shown to inhibit cell proliferation in vitro, whereas SSTR2 and SSTR3 may additionally induce apoptosis [4]. These direct antitumor effects appear to be regulated primarily through activation of phosphotyrosine phosphatases and mitogen-activated protein kinase (MAPK) signaling [5]. In addition to its inhibitory effect on growth factor and hormone secretion, SST has been shown to exert a number of other indirect antitumor actions including antiangiogenic and immunomodulatory effects [6].

The clinical utility of natural SST is limited by its very short circulation half-life (1.5-3 min). A number of synthetic SST analogues with improved pharmacokinetic profiles have been developed of which octreotide and lanreotide are now widely used for the biotherapy of acromegaly and GEP-NETs $[7,8]$. Both compounds provide excellent control of hypersecretory-associated symptoms. In contrast to their natural counterparts which bind to all five SSTR subtypes with high affinity, octreotide and lanreotide predominantly bind to SSTR2 [9].

The results of several uncontrolled clinical studies in NETs also suggest octreotide and lanreotide possess antiproliferative activity, mostly resulting in tumor stabilization [8]. The PROMID study, a prospective placebo-controlled clinical phase IIIb study with octreotide long-acting release $30 \mathrm{mg}$ in 85 patients with well-differentiated metastatic midgut NETs, reported a significant effect on median time to tumor progression with 14.3 months in the octreotide long-acting release group versus 6 months in the placebo group [10].

It is now known that SSTR subtypes can undergo homo- or heterodimerization, thereby enhancing ligand binding, internalization and signal transduction [11]. SSTRs have also been demonstrated to form heterodimers with other $G$ protein-coupled receptors such as the $\mu$-opioid or the dopamine type 2 receptor (D2R) [12]. Thus, novel SST analogues which bind with high affinities to multiple SSTR subtypes and chimeric compounds binding SSTRs and D2R have been developed. Such com-
Table 1. Human SSTR subtype specificity [Ki; dissociation constant (nM)]. Zhang S, Datta R and Culler MD 2013 [pers. commun.]

\begin{tabular}{lrlrrrr}
\hline Compound & SSTR1 & SSTR2 & SSTR3 & SSTR4 & SSTR5 & D2R \\
\hline BIM-23A758 & 549 & 0.2 & $>1,000$ & $>1,000$ & 43 & 14 \\
BIM-23A760 & 142 & 0.2 & 40 & 471 & 6 & 5 \\
BIM-23023 & $>1,000$ & 0.2 & 87 & $>1,000$ & 5 & $>1,000$ \\
BIM-53097 & ND & ND & ND & ND & ND & 51 \\
\hline
\end{tabular}

$\mathrm{ND}=$ Not done

pounds have been shown to be more effective in suppressing growth hormone and prolactin secretion from cultured human growth hormone-secreting pituitary tumors than monoreceptor ligands alone [13-15]. As the majority of GEP-NETs coexpress SSTRs and D2R, such compounds might offer novel therapeutic opportunities $[16,17]$.

In this study we analyze the effects of the novel SSTR2/ D2R chimeric compounds BIM-23A760 and BIM23A758 in comparison to the selective SSTR2 agonist BIM-23023 and the selective D2R agonist BIM-53097 (table 1) on three human NET cell lines of heterogeneous origin. Although a current clinical phase 2 study with BIM-23A760 in NETs (NCT01018953) has been terminated, our data with BIM-23A758 can demonstrate as a proof of principle the antitumoral effects of SSTR2/D2R chimeric compounds in NETs preselected for coexpression of SSTRs and D2R.

\section{Materials and Methods}

\section{Cell Culture}

Human pancreatic neuroendocrine BON1 tumor cells were kindly provided by R. Göke (Marburg, Germany) and were cultured in DMEM/F12 (1:1) medium (Gibco/Invitrogen, Karlsruhe, Germany). Human midgut carcinoid GOT1 cells were kindly provided by Ola Nilsson (Göteborg, Sweden). Human bronchopulmonary neuroendocrine NCI-H727 tumor cells were purchased from ATCC (Manassas, Va., USA). GOT1 and NCI-H727 cells were cultured in RPMI-1640 medium (PAA, Pasching, Austria). All media were supplemented with 10\% FCS (Biochrom, Berlin, Germany), $1 \%$ penicillin/streptomycin (Gibco) and $0.4 \%$ amphotericin B (Biochrom). GOT1 culture medium was additionally supplemented with $0.135 \mathrm{IU} / \mathrm{ml}$ insulin and $5 \mu \mathrm{g} / \mathrm{ml}$ apo-transferrin. All cells were cultured at $37^{\circ} \mathrm{C}$ in a $5 \% \mathrm{CO}_{2}$ atmosphere.

\section{Reagents}

BIM-23A760, BIM-23A758, BIM-23023 and BIM-53097 were kindly provided by Michael Culler (Ipsen, Milford, Mass., USA). Compounds BIM-23A760, BIM-23A758 and BIM-23023 were dis- 


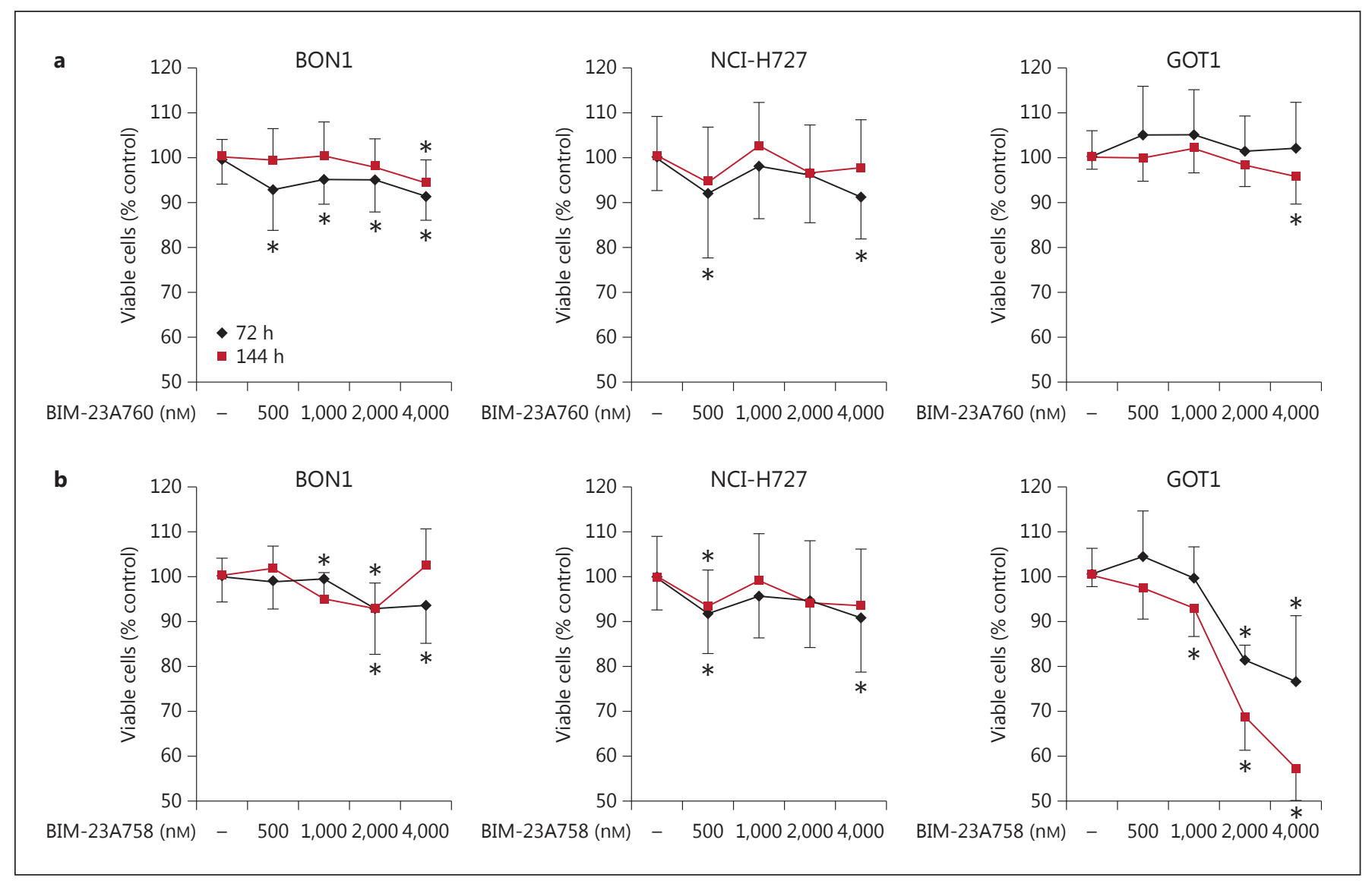

Fig. 1. BIM-23A758 potently decreases GOT1 cell viability. BON1, NCI-H727 and GOT1 cells were incubated with indicated concentrations of BIM-23A760 (a) or BIM-23A758 (b) for 72 and 144 h, respectively. Cell viability was measured with the Cell Titer 96 kit (Promega). Shown are the mean values \pm SD of three independently performed experiments ( $n=6$ /group for each experiment). ${ }^{*} \mathrm{p}<0.05$ vs. untreated control.

solved in $0.2 \%$ BSA. BIM-53097 was initially dissolved in $0.15 \%$ ethanol; further dilutions were performed in $0.2 \%$ BSA. Therefore, control groups always contained $0.15 \%$ ethanol. Sulpiride was purchased from Sigma-Aldrich (St. Louis, Mo., USA).

\section{Assessment of Cell Viability}

All compounds were added once at the beginning of the experiment for the indicated time points. Metabolic activity was measured with Cell Titer $96 \mathrm{AQ}_{\text {ueous }}$ One Solution Cell Proliferation Assay (Promega, Madison, Wis., USA) according to the manufacturer's instructions. Following $3 \mathrm{~h}$ of incubation with Cell Titer 96 solution, absorbance at $492 \mathrm{~nm}$ was determined using an ELISA plate reader.

\section{RNA Isolation and Quantitative RT-PCR}

RNA isolation and quantitative RT-PCR (qRT-PCR) were performed as described previously [18] using the following primers for amplification: human SSTR2 forward and reverse: $5^{\prime}$-GGCATGTTTGACTTTGTGGTG- ${ }^{\prime}$ and $5^{\prime}$-GTCTCATTCAGCCGGGATTT-3', human SSTR5 forward and reverse: $5^{\prime}$-CTGGTGTTT-
GCGGGATGTT- $3^{\prime}$ and $5^{\prime}$-GAAGCTCTGGCGGAAGTTGT- ${ }^{\prime}$, human D2R-long (L) forward and reverse: $5^{\prime}$-CAACTGTACTCACCCCGAG- $3^{\prime}$ and $5^{\prime}$-GGCTGTACCGGGTCCTCTC-3', human D2R-short (S) forward and reverse: $5^{\prime}$-CACTAAAGGAGGCTGC- $3^{\prime}$ and $5^{\prime}$-GGCTGTACCGGGTCCTCTC- ${ }^{\prime}$, and human GAPDH forward and reverse: $5^{\prime}$-ACCCACTCCTCCACCTTTGA- $3^{\prime}$ and $5^{\prime}$-CTGTTGCTGTAGCCAAATTCGT-3'. PCR was performed using Platinum Taq DNA Polymerase (Invitrogen, Carlsbad, Calif., USA) and SYBR Green under the following conditions: 35 cycles of denaturing at $94^{\circ} \mathrm{C}$ for $30 \mathrm{~s}$, annealing at $55^{\circ} \mathrm{C}$ (D2R: $62^{\circ} \mathrm{C}$ ) for $30 \mathrm{~s}$ and extension at $72^{\circ} \mathrm{C}$ for $30 \mathrm{~s}$. Relative expression levels were calculated with the $\Delta \Delta \mathrm{C}_{\mathrm{t}}$ method [19] using internal GAPDH for normalization.

\section{Protein Extraction, Immunoprecipitation and Western Blotting}

Protein extraction and Western blotting were done as previously described in detail [20]. Primary antibodies used were pAkt (Ser473), pan-Akt, pMEK, MEK, pERK-1/2, ERK-1/2, pp70S6K, p70S6K, p4E-BP1, 4E-BP1, pMDM2, cyclin D1, cyclin D3, p27kip1, 


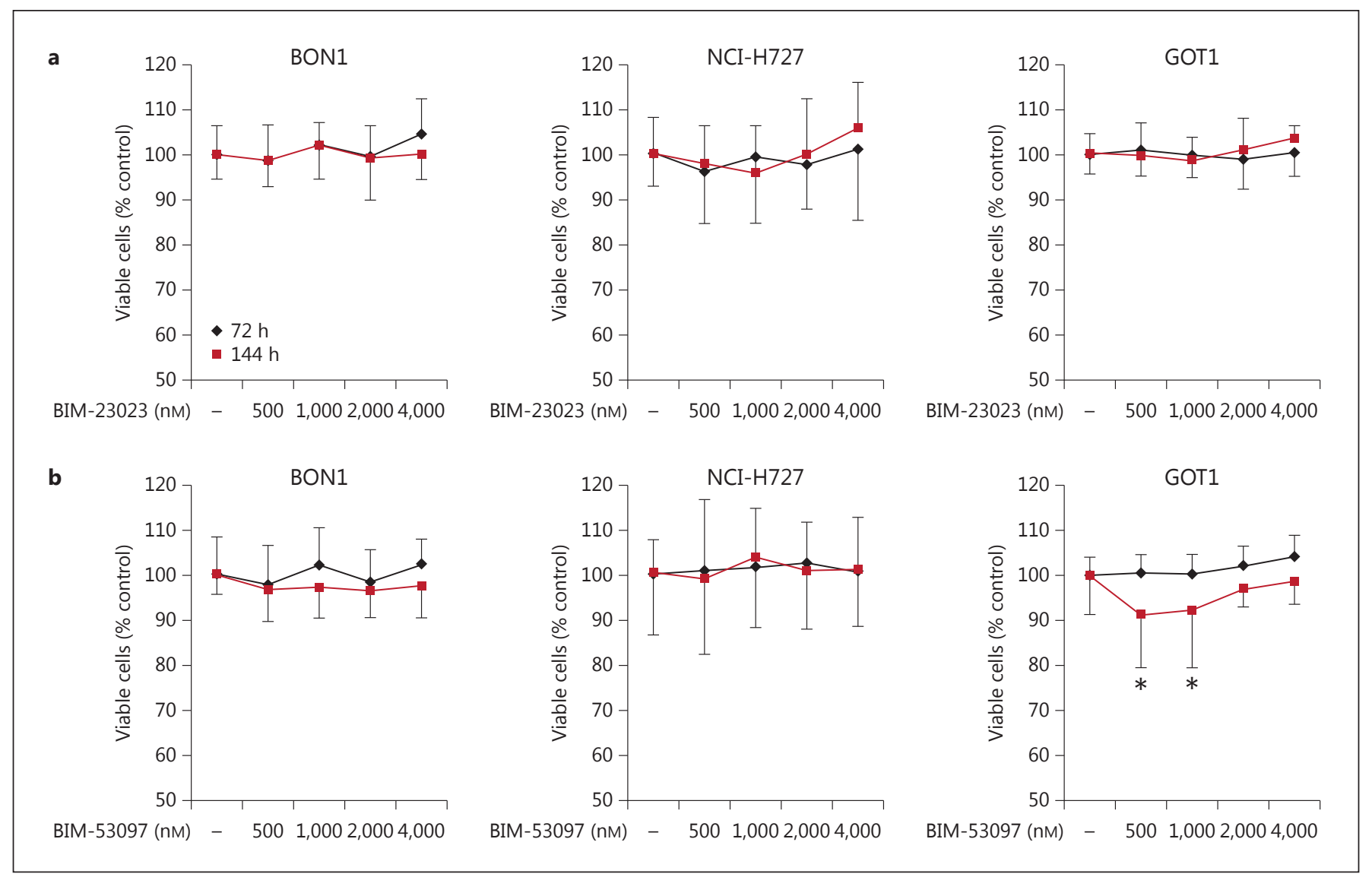

Fig. 2. Effect of monoreceptor ligands on NET cell viability. BON1, NCI-H727 and GOT1 cells were incubated with indicated concentrations of BIM-23023 (a) or BIM-53097 (b) for 72 and 144 h, respectively. Cell viability was measured with the Cell Titer 96 kit (Promega). Shown are the mean values \pm SD of three independently performed experiments $\left(\mathrm{n}=6\right.$ /group for each experiment). ${ }^{*} \mathrm{p}<0.05$ vs. untreated control.

PARP, caspase-3, Bcl-XL (Cell Signaling, Danvers, Mass., USA), Bcl-2 (BD, Franklin Lakes, N.J., USA), cleaved caspase-3 (R\&D Systems, Wiesbaden-Nordenstadt, Germany) and $\beta$-actin (Abcam, Cambridge, UK).

\section{Quantification of DNA Fragmentation and Cell Cycle} Analysis

The rate of apoptotic cell death was quantified by determining DNA fragmentation according to Nicoletti et al. [21]. Briefly, cells were incubated for $24 \mathrm{~h}$ in a hypotonic buffer $(0.1 \%$ sodium citrate, $0.1 \%$ Triton $\mathrm{X}-100,50 \mu \mathrm{g} / \mathrm{ml}$ propidium iodide) and analyzed by flow cytometry on a FACSCalibur analyzer (BD) using CellQuest software (BD). Nuclei to the left of the $\mathrm{G}_{1}$-peak containing hypodiploid DNA were considered apoptotic.

\section{Statistical Analysis}

Statistical analysis was done using a two-tailed Student $t$ test. $\mathrm{p}<0.05$ was considered statistically significant.

\section{Results}

\section{BIM-23A758 Decreases GOT1 Cell Viability}

To test the antitumor potential of SSTR2/D2R chimeric compounds in different human NET cell lines, pancreatic BON1 cells, bronchus typical carcinoid NCI-H727 cells and midgut GOT1 cells were incubated with increasing concentrations of BIM-23A760, BIM-23A758, BIM23023 or BIM-53097 for $72 \mathrm{~h}$ and $144 \mathrm{~h}$, respectively. In the low-dose range (tested concentrations: 1, 10 and 100 $\mathrm{nM}$ ), none of the tested cell lines responded to any of the substances with significant antitumor effects (data not shown). At higher concentrations (tested concentrations: $500,1,000,2,000$ and 4,000 nM), BIM-23A760 induced minor but significant short-term effects in reducing cell viability - especially in BON1 cells (max. reduction of cell viability at $500 \mathrm{nM}$ to approx. $93 \%, \mathrm{p}<0.05$; fig. 1a). In 
Fig. 3. GOT1 cells have high expression levels of SSTR2 and D2R. mRNA expression levels of D2R-L (a), D2R-S (b), SSTR2 (c) and SSTR5 (d) in BON1, NCI-H727 and GOT1 cells were verified by qPCR. Receptor mRNA expression in BON1 and NCI-H727 cells relative to NCI-H727 cells was calculated using the comparative $\Delta \Delta \mathrm{C}_{\mathrm{t}}$ method and internal GAPDH for normalization. Shown are the mean values \pm SD of three independently performed experiments ( $n=2$ /group for each experiment).
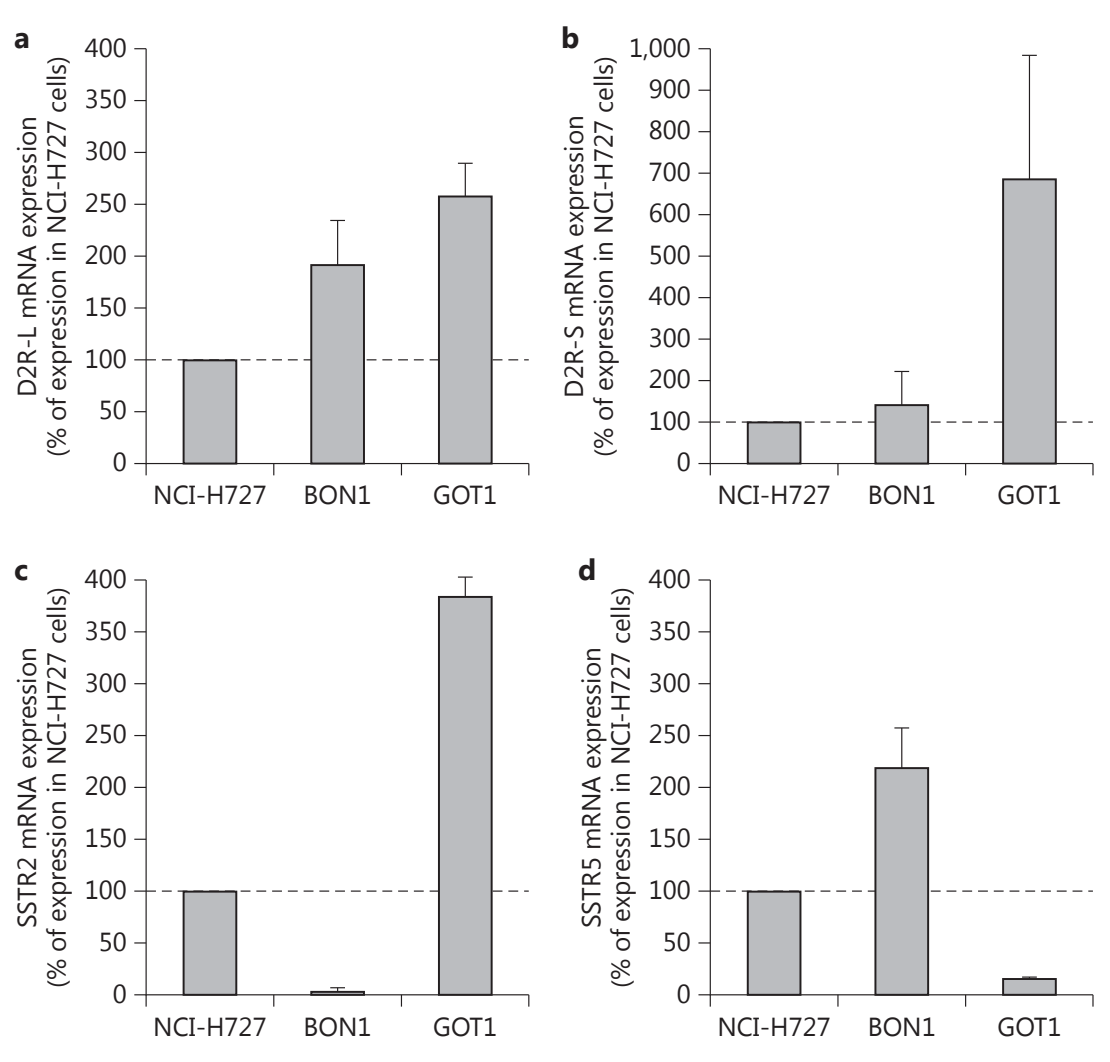

contrast, BIM-23A758 dose- and time-dependently decreased the viability of GOT1 cells to approximately $56 \%$ while having no or only minor effects on the viability of BON1 and NCI-H727 cells (fig. 1b). GOT1 cells were also slightly responsive to the D2R agonist BIM-53097 (max. reduction of cell viability at $500 \mathrm{nM}$ to $91 \%, \mathrm{p}<0.05$; fig. 2b). However, none of the tested cell lines was responsive to the SSTR2 agonist BIM-23023 (fig. 2a).

\section{GOT1 Cells Have High Expression Levels of SSTR2 and $D 2 R$}

To identify the molecular determinants of response to the SSTR2/D2R chimeric compounds, basal mRNA levels of SSTR2, SSTR5 and the two splice variants of D2R, D2R-L and D2R-S, were analyzed by qRT-PCR in NCIH727, BON 1 and GOT1 cells. All three cell lines expressed the tested receptor subtypes (fig. 3). Consistent with their strong response to BIM-23A758 in cell viability assays, GOT1 cells showed the highest expression levels of SSTR2, D2R-L and D2R-S mRNA among the tested cell lines (fig. 3). In contrast, GOT1 cells expressed low levels of SSTR5 mRNA (fig. 3d).

\section{Expression Profiles of SSTR 1 and SSTR 3}

The fact that relatively high doses of BIM-23A758 were needed to achieve significant antitumor effects in GOT1 cells $(\geq 1,000 \mathrm{nM})$ might possibly reflect a contribution of other SSTRs with lower binding affinities. We thus additionally analyzed basal mRNA levels of SSTR1, SSTR3 and SSTR4 by qRT-PCR. While SSTR4 was not detectable in any of the tested cell lines, GOT1 cells showed moderate expression of SSTR1 and SSTR3 (fig. 4), but the highest relative expression was observed in BON1 cells.

\section{Sulpiride Partially Inhibits BIM-23A758-Induced} Antitumor Effects in GOT1 Cells

To assess the role of $\mathrm{D} 2 \mathrm{R}$ in the cytotoxic response to BIM-23A758, GOT1 cells were cotreated with BIM23A758 and the selective D2R antagonist sulpiride. As shown in figure 5 , sulpiride could partially rescue GOT1 cells from BIM-23A758-induced antitumor effects.

\section{BIM-23A758 Induces Apoptosis in GOT1 Cells}

In order to identify the mechanism responsible for the decrease of cell viability in response to BIM-23A758, we 
Fig. 4. mRNA expression levels of SSTR1 and SSTR3 in NET cells. mRNA expression levels of SSTR1 (a) and SSTR3 (b) in BON1, NCI-H727 and GOT1 cells were determined by qPCR. Receptor mRNA expression in BON1 and NCI-H727 cells relative to NCI-H727 cells was calculated using the comparative $\Delta \Delta C_{t}$ method and internal GAPDH for normalization. Shown are the mean values \pm SD of three independently performed experiments $(n=2$ /group for each experiment).
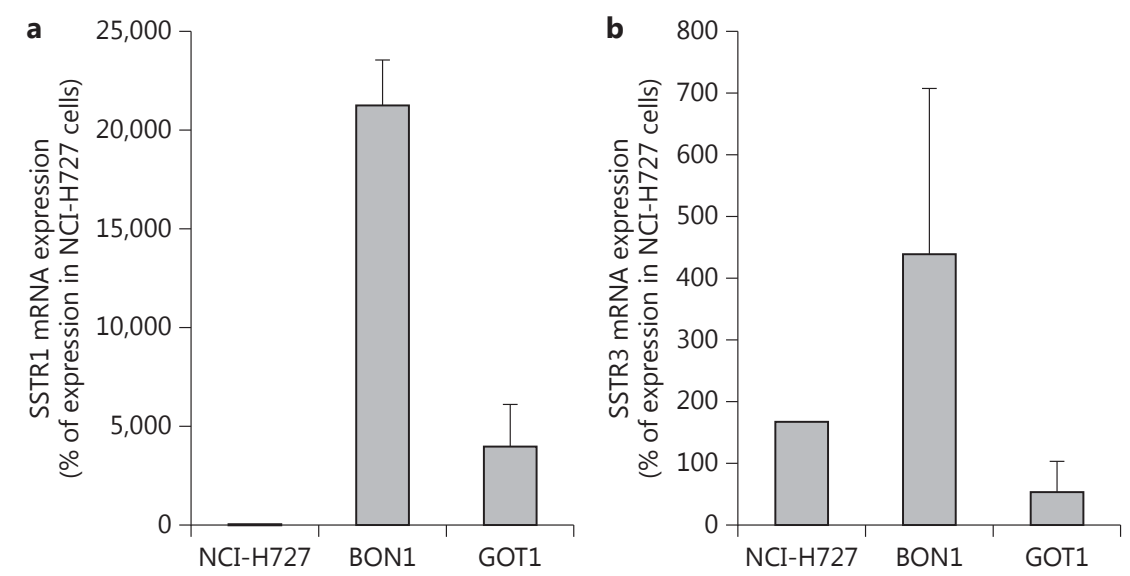

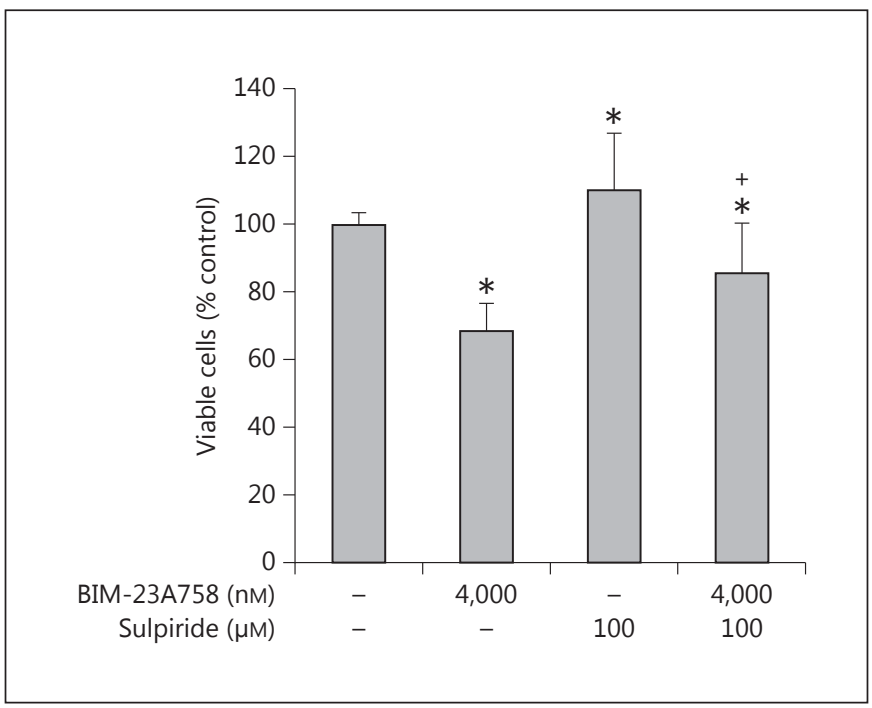

Fig. 5. Sulpiride partially inhibits BIM23A758-induced antitumor effects in GOT1 cells. GOT1 cells were incubated with BIM23A758 $(4,000 \mathrm{nM})$, sulpiride $(100 \mu \mathrm{M})$, or a combination of both for $72 \mathrm{~h}$. Cell viability was measured with the Cell Titer 96 kit (Promega). Shown are the mean values \pm SD of three independently performed experiments $\left(\mathrm{n}=6\right.$ /group for each experiment). ${ }^{*} \mathrm{p}<$ 0.05 vs. untreated control; ${ }^{+} \mathrm{p}<0.05$ vs. BIM-23A758-treated cells.

performed FACS analysis of GOT1 cells treated with BIM-23A760, BIM-23A758, BIM-23023 or BIM-53097. As shown in figure 6a, BIM-23A758 increased the fraction of cells with subG1-DNA content. Specific induction of apoptosis was confirmed by decreased Bcl-XL and $\mathrm{Bcl}-2$ protein expression and induction of cleaved cas- pase-3 (fig. 6b). BIM-23A758 treatment resulted in a relative decrease of cells in G0/1, S and G2M, likely due to increased subG1, while Western blot analysis showed no significant changes in the expression of cyclin D1, cyclin D3 and p27kip1 (data not shown).

\section{BIM-23A758 Inhibits Akt and Erk Signaling in GOT1 Cells}

It has previously been reported that SSTR2/D2R chimeric molecules can affect Akt and MAPK signaling in a cell type-specific manner [22]. Consistent with its antitumor effect, BIM-23A758 significantly inhibited Akt and MAPK signaling in GOT1 cells (fig. 7). In addition, BIM23A758 inhibited the phosphorylation of the Akt downstream targets p70S6K, 4E-BP1 and pMDM2 (fig. 7).

\section{Discussion}

In this study we tested the antitumor potential of the novel SSTR2/D2R chimeric compounds BIM-23A760 and BIM-23A758 in comparison to the selective SSTR2 agonist BIM-23023 and the selective D2R agonist BIM53097 on three human NET cell lines of heterogeneous origin. We show that BIM-23A758 is effective in the human midgut carcinoid cell line GOT1, while having only minor effects on human pancreatic BON1 and human bronchus carcinoid NCI-H727 cells, although NCI-H727 cells express relatively high levels of SSTRs compared to other NET cell lines [23].

Different responses to SSTR2/D2R chimeras seem likely to be dependent on cell type-specific SST and do- 
Fig. 6. BIM-23A758 induces apoptosis in GOT1 cells. GOT1 cells were incubated with BIM-23A760, BIM-23A758, BIM23023 or BIM-53097 (4,000 nM each) for $72 \mathrm{~h}(\mathbf{a})$ or $48 \mathrm{~h}$ (b). a Subsequently, the fraction of cells with subG1 content was examined by flow cytometry. Shown is the mean value \pm SD of four independently performed experiments $(* \mathrm{p}<0.05)$. b Protein expression of Bcl-XL, Bcl-2, cleaved caspase- 3 and $\beta$-actin loading control were evaluated by Western blot. Shown is one representative blot out of three performed.

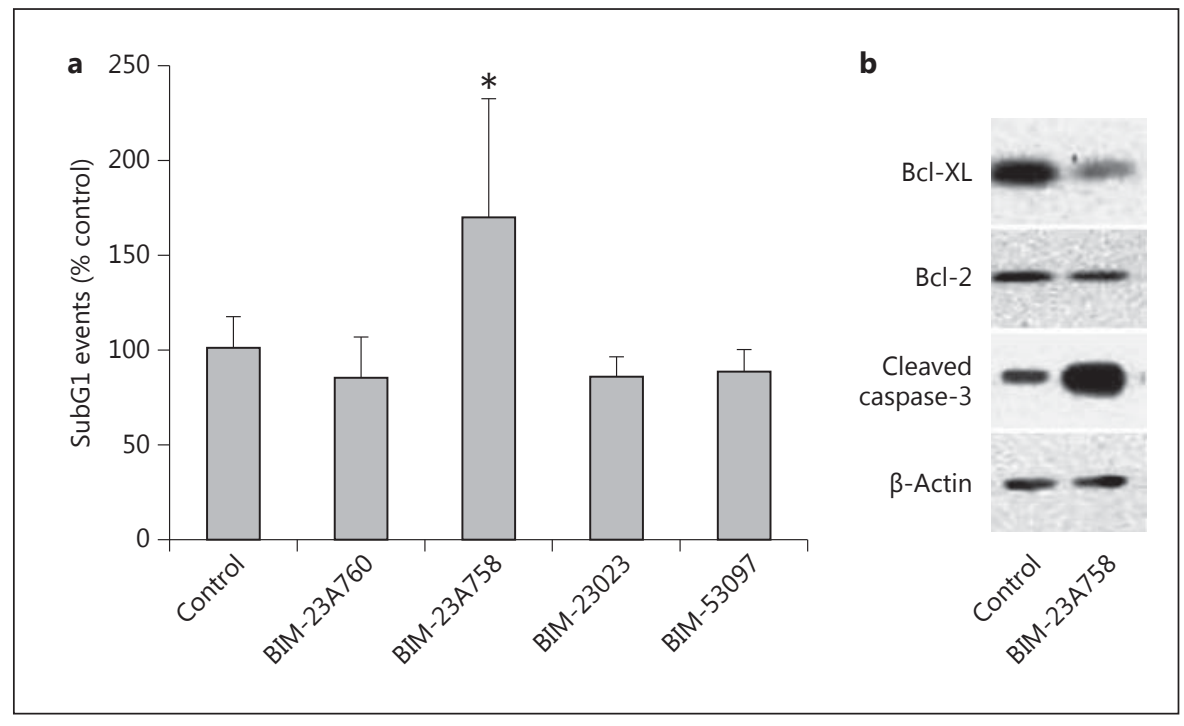

pamine receptor expression profiles and individual receptor signaling. Indeed, qRT-PCR revealed that GOT1 cells - compared to NCI-H727 and BON1 cells - express high levels of both SSTR2 and D2R. In particular, GOT1 cells highly express the short transcript variant of D2R. Though both isoforms of D2R can transduce the intracellular signal correctly [24], the expression of D2R-S seems more important for a favorable growth inhibitory response to dopamine agonists in pituitary adenomas than the expression of D2R-L [25-27]. It has also been shown that D2R-L is mostly retained in the perinuclear region around the Golgi apparatus, whereas D2R-S is predominantly localized at the plasma membrane and might therefore be more accessible to dopamine agonists [28].

It should be noted that the expression of D2R in GEPNETs, compared to pituitary adenomas or normal brain tissue, is extremely low [22, 29]. However, constitutive or ligand-induced formation of SSTR/D2R homo- or heterodimers may lead to increased functional activity [12]. Thus, even low receptor densities might be sufficient to yield potent antitumor effects in response to novel SSTR/ D2R chimeric compounds. GOT1 cells were hardly responsive to the single SSTR2 and D2R ligands BIM-23023 and BIM-53097, while they were responsive to the SSTR2/ D2R chimeric compound BIM-23A758. Both dopamine and SST activity were required for the observed antitumor effect of BIM-23A758 as treatment with the dopamine antagonist sulpiride could only partially block the chimera effect. These findings are consistent with a study by Saveanu et al. [30] who demonstrated that combined

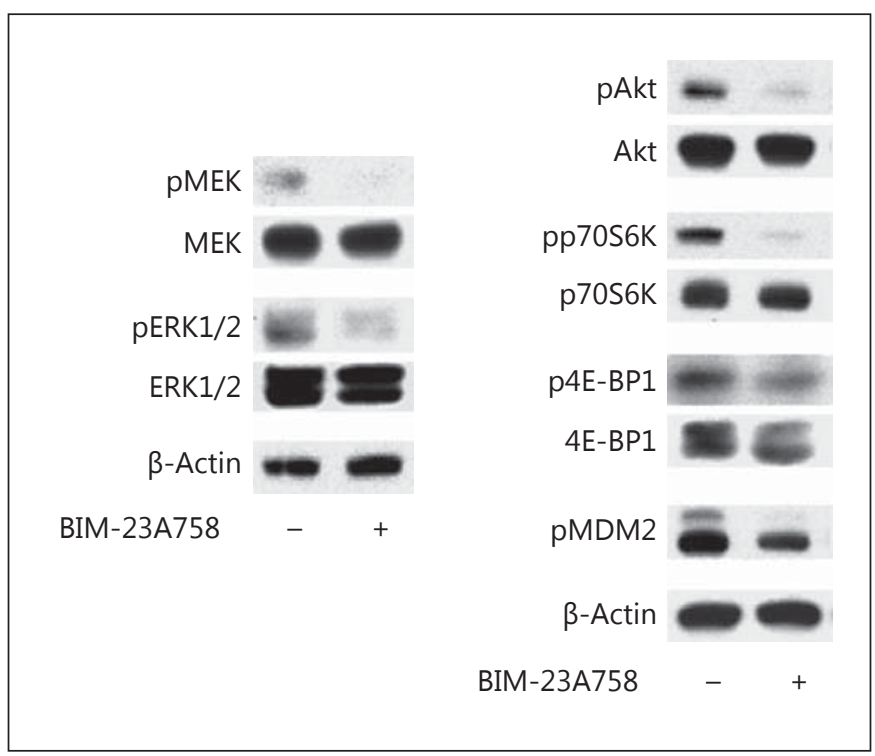

Fig. 7. BIM-23A758 inhibits Akt- and Erk signaling in GOT1 cells. GOT1 cells were incubated with BIM-23A758 (4,000 nM) for $2 \mathrm{~h}$. Subsequently, protein expression of phosphorylated and total MEK, Erk1/2, Akt, p70S6K, 4E-BP1 and phosphorylated MDM2 was evaluated by Western blot analysis. Shown is one representative blot out of three performed.

treatment with sulpiride and an SSTR2 antagonist was required to achieve full reversal of the growth hormonesuppressing effect of the SSTR2/D2R chimeric compound BIM-23A287 on human pituitary somatotroph adenoma cells [30]. 
However, it cannot be excluded that the lack of responsiveness to BIM-23023 was due to the compound as GOT1 cells xenografted to nude mice is a well-established model for peptide receptor-based radiotherapy with SST analogues [31]. As we did not test any other SSTR2 agonists, the missing antitumoral effect of BIM-23023 is no evidence to conclude that GOT1 cells in general fail to respond to SSTR2 agonists.

In contrast to previous studies on pituitary cells [32], we employed relatively large doses of BIM chimeras (500-4,000 nM) as low doses up to $100 \mathrm{nM}$ had no significant antitumor effect on the tested NET cell lines. This observation might possibly reflect the contribution of other SSTRs (e.g. SSTR3) with lower binding affinities (table 1). The fact that GOT1 responded to BIM-23A758 but not to BIM-23A760 might be attributed to slightly different binding affinities for the SSTR1-5 subtypes and D2R (table 1). Successful treatment with chimeric compounds might thus require a perfect match between receptor profile and binding affinities.

In order to reveal the signaling pathways implicated in BIM-23A758-induced antiproliferative and apoptotic effects we analyzed the activation status of MAPK and Akt signaling. While dopamine-induced antiproliferative and apoptotic effects have been shown to be primarily mediated by p38 MAPK and Erk [24, 33, 34], SSTR-induced antitumor action involves the inhibition of PI(3)K/Akt signaling [35]. In our study, BIM-23A758 potently inhibited Akt and its downstream targets p70S6K, 4E-BP1 and MDM2 in GOT1 cells. However, while previous studies have demonstrated an increase of ERK1/2 phosphorylation in response to dopamine or SSTR2/D2R chimeric compounds in various cell types [22,33,34], BIM-23A758 potently decreased ERK1/2 phosphorylation in GOT1 cells. Consistent with our results, a recent study reported inhibition of ERK1/2 signaling in NCI-H727 cells after treatment with the SSTR3/DR2 chimeric compound BIM-23A761 [22]. These data suggest that Erk1/2 phosphorylation or dephosphorylation in response to D2R activation is cell type-specific.

In conclusion, our data show that NET cells of heterogeneous origin respond differently to specific SSTR2 agonistic, D2R agonistic and SSTR2/D2R chimeric compounds. The extent of response seems to depend on the individual SST and dopamine receptor profile. In particular, a sufficient expression of the short transcript variant of DR2 might play a pivotal role for effective treatment.

To our knowledge, data on BIM-23A758 pharmakokinetics are not available. In contrast to in vitro data, clinical studies have revealed that chronic administration of BIM-23A760 in humans leads to the production of a metabolite which gradually accumulates and interferes with the activity of the parent compound [36]. Therefore, both BIM-23A760 and BIM-23A758 are currently not under consideration for clinical use, but should rather be considered as prototypes for this chimeric class of compounds. Consequently, efforts are ongoing to create optimized second generation chimera, which might be a promising treatment strategy for NETs expressing an appropriate receptor profile.

\section{Disclosure Statement}

This study was supported by a restricted research grant to C.J. Auernhammer from Ipsen Germany. C.J. Auernhammer has also received research contracts (Novartis), lecture honoraria (Ipsen, Novartis, Pfizer, Amgen, Roche) and advisory board honoraria (Ipsen, Novartis).

\section{References}

1 Brazeau P, et al: Hypothalamic polypeptide that inhibits the secretion of immunoreactive pituitary growth hormone. Science 1973;179: 77-79.

2 Reichlin S: Somatostatin. N Engl J Med 1983; 309:1495-1501.

-3 Moller LN, et al: Somatostatin receptors. Biochim Biophys Acta 2003;1616:1-84.

4 Culler MD, et al: Somatostatin analogs for the treatment of neuroendocrine tumors. Cancer Metastasis Rev 2011;30(suppl 1):9-17.

5 Florio T: Molecular mechanisms of the antiproliferative activity of somatostatin receptors (SSTRs) in neuroendocrine tumors. Front Biosci 2008;13:822-840.
6 Florio T, et al: Somatostatin inhibits tumor angiogenesis and growth via somatostatin receptor-3-mediated regulation of endothelial nitric oxide synthase and mitogen-activated protein kinase activities. Endocrinology 2003; 144:1574-1584

7 Murray RD, Melmed S: A critical analysis of clinically available somatostatin analog formulations for therapy of acromegaly. J Clin Endocrinol Metab 2008;93:2957-2968.

8 Modlin IM, et al: Review article: somatostatin analogues in the treatment of gastroenteropancreatic neuroendocrine (carcinoid) tumours. Aliment Pharmacol Ther 2010;31: 169-188.
9 Bruns C, et al: SOM230: a novel somatostatin peptidomimetic with broad somatotropin release inhibiting factor (SRIF) receptor binding and a unique antisecretory profile. Eur J Endocrinol 2002;146:707-716.

10 Rinke A, et al: Placebo-controlled, doubleblind, prospective, randomized study on the effect of octreotide LAR in the control of tumor growth in patients with metastatic neuroendocrine midgut tumors: a report from the PROMID Study Group. J Clin Oncol 2009;27:4656-4663.

11 Rocheville M, et al: Subtypes of the somatostatin receptor assemble as functional homo- and heterodimers. J Biol Chem 2000;275:7862-7869. 


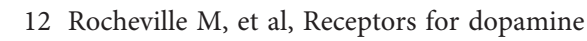
and somatostatin: formation of hetero-oligomers with enhanced functional activity. Science 2000;288:154-157.

13 Saveanu A, et al: Bim-23244, a somatostatin receptor subtype 2- and 5-selective analog with enhanced efficacy in suppressing growth hormone (GH) from octreotide-resistant human GH-secreting adenomas. J Clin Endocrinol Metab 2001;86:140-145.

14 Ren SG, et al: Suppression of rat and human growth hormone and prolactin secretion by a novel somatostatin/dopaminergic chimeric ligand. J Clin Endocrinol Metab 2003;88: 5414-5421.

15 Jaquet P, et al: Efficacy of chimeric molecules directed towards multiple somatostatin and dopamine receptors on inhibition of GH and prolactin secretion from $\mathrm{GH}$-secreting pituitary adenomas classified as partially responsive to somatostatin analog therapy. Eur J Endocrinol 2005; 153:135-141.

16 Srirajaskanthan R, et al: Expression of somatostatin and dopamine 2 receptors in neuroendocrine tumours and the potential role for new biotherapies. Neuroendocrinology 2009; 89:308-314.

17 Diakatou E, et al: Somatostatin and dopamine receptor profile of gastroenteropancreatic neuroendocrine tumors: an immunohistochemical study. Endocr Pathol 2011;22:2430.

18 Brand S, et al: IL-22 is increased in active Crohn's disease and promotes proinflammatory gene expression and intestinal epithelial cell migration. Am J Physiol Gastrointest Liver Physiol 2006;290:G827-G838.

19 Schmittgen TD, Livak KJ: Analyzing realtime PCR data by the comparative C(T) method. Nat Protoc 2008;3:1101-1108.
20 Zitzmann K, et al: Novel interferon-lambdas induce antiproliferative effects in neuroendocrine tumor cells. Biochem Biophys Res Commun 2006;344:1334-1341.

21 Nicoletti I, et al: A rapid and simple method for measuring thymocyte apoptosis by propidium iodide staining and flow cytometry. J Immunol Methods 1991;139:271-279.

22 Kidd M, et al: Differential cytotoxicity of novel somatostatin and dopamine chimeric compounds on bronchopulmonary and small intestinal neuroendocrine tumor cell lines. Cancer 2008;113:690-700.

23 Li SC, et al: The somatostatin analogue octreotide inhibits growth of small intestine neuroendocrine tumour cells. PLoS One 2012;7:e48411.

24 An JJ, et al: Anti-proliferative effects and cell death mediated by two isoforms of dopamine D2 receptors in pituitary tumor cells. Mol Cell Endocrinol 2003;206:49-62.

25 Renner U, et al: Heterogeneous dopamine D2 receptor subtype messenger ribonucleic acid expression in clinically nonfunctioning pituitary adenomas. J Clin Endocrinol Metab 1998;83:1368-1375.

26 Pivonello R, et al: Dopamine receptor expression and function in clinically nonfunction ing pituitary tumors: comparison with the effectiveness of cabergoline treatment. J Clin Endocrinol Metab 2004;89:1674-1683.

27 Sarkar DK, et al: Dopamine, dopamine D2 receptor short isoform, transforming growth factor (TGF)-beta1, and TGF-beta type II receptor interact to inhibit the growth of pituitary lactotropes. Endocrinology 2005;146: 4179-4188.

28 Takeuchi Y, Fukunaga K: Differential subcellular localization of two dopamine D2 receptor isoforms in transfected NG108-15 cells. J Neurochem 2003;85:1064-1074.
29 O'Toole D, et al: The analysis of quantitative expression of somatostatin and dopamine receptors in gastro-entero-pancreatic tumours opens new therapeutic strategies. Eur J Endocrinol 2006;155:849-857.

30 Saveanu A, et al: Demonstration of enhanced potency of a chimeric somatostatin-dopamine molecule, BIM-23A387, in suppressing growth hormone and prolactin secretion from human pituitary somatotroph adenoma cells. J Clin Endocrinol Metab 2002;87:5545-5552.

31 Nilsson O, et al: GOT1 xenografted to nude mice: a unique model for in vivo studies on SSTR-mediated radiation therapy of carcinoid tumors. Ann NY Acad Sci 2004;1014: 275-279.

32 Florio T, et al: Efficacy of a dopamine-somatostatin chimeric molecule, BIM-23A760, in the control of cell growth from primary cultures of human non-functioning pituitary adenomas: a multi-center study. Endocr Relat Cancer 2008; 15:583-596.

33 Junn E, Mouradian MM: Apoptotic signaling in dopamine-induced cell death: the role of oxidative stress, p38 mitogen-activated protein kinase, cytochrome $\mathrm{c}$ and caspases. J Neurochem 2001;78:374-383.

34 Ferone D, et al: The clinical-molecular interface of somatostatin, dopamine and their receptors in pituitary pathophysiology. J Mol Endocrinol 2009;42:361-370.

-35 Theodoropoulou M, et al: Octreotide, a somatostatin analogue, mediates its antiproliferative action in pituitary tumor cells by altering phosphatidylinositol 3-kinase signaling and inducing Zac1 expression. Cancer Res 2006; 66:1576-1582.

36 Culler MD: Somatostatin-dopamine chimeras: a novel approach to treatment of neuroendocrine tumors. Horm Metab Res 2011;43: 854-857. 